\title{
Ageing and Incidence of Osteoarthritis of the Knee Joint, Lumbar and Cervical Spine at the University of Ibadan, Nigeria
}

\author{
Okanlawon F.A. \\ Department of Nursing, College of Medicine, University of Ibadan, Ibadan, Nigeria \\ Correspondence \\ F.A. Okanlawon; E-mail: funmilayookanlawon@yahoo.com; Tel.: 08055071838
}

\begin{abstract}
SUMMARY
It has been observed that the most frequently reported disorder of the elderly is osteoarthritis associated with ageing. The elderly thus tend to use health services more often. This study examined the incidence, age and gender distribution of osteoarthritis of the knee joint, lumbar and cervical spine among the elderly at the University of Ibadan Health Centre.

The study adopted anon-experimental descriptive design. The study population consisted of adults aged 45-85 years diagnosed with osteoarthritis. The respondents consisted of 209 males and 277 females. Retrospective records of cases of osteoarthritis between July 2007 and June 2008 were retrieved with permission. Data was analysed using the chi-square test to determine the relationship between gender, age and occurrence of osteoarthritis.

The results showed that the incidence of osteoarthritis in the lumbar spine was the highest $-175(36 \%)$, followed by the cervical spine $-159(32.7 \%)$, and the knee joint-152 (31.3\%). There was a significant difference in the distribution of osteoarthritis between gender and within the age groups $(\mathrm{P}=0.000)$. Osteoarthritis of the lumbar spine was the highest in males within the age groups of 61-65, followed by 45-50, $56-60$, and 51 - 55; whereas in the females, osteoarthritis of the knee joint was the highest within the age groups of $56-60$, followed by $45-50,61-65,81-85$ and 71-75.

The incidence of osteoarthritis seemed the same in males and females but the distribution varied between gender and within age groups. It was recommended that further studies should be considered in the area of the relationship between the nature of job and incidence of osteoarthritis to find out why osteoarthritis of the knee joint, the lumbar and cervical spine are peculiar to some individuals.
\end{abstract}

KEY WORDS: Ageing, osteoarthritis, knee joint, lumbar spine, cervical spine

\section{INTRODUCTION}

Ageing, as described by WHO (2003), is a series of gradual but complex biopsychosocial changes that occur in all living organisms. It is a continuous process of progressive change in all the structures and functions of the body, starting at conception and ending with death. Different parts of the human body begin to decline at different ages and deteriorate at different rates. People then begin to use health services more often. It has been reported that elderly people use a disproportionately higher share of health services than other age groups, with people over 65 years having twice as many contacts with the health care system than those under 65 years (USAHHS, 2002).

As reported by the US Bureau of the Census (2002), the very old ( 85 years and above) represent the fastest growing segment of the total population and they are the 
major users of health services. Valentino (2002) also confirms that elderly people are greater users of health care services than any other population segment. As noted by Valentino, the implication is that nurses of the future must be prepared to work effectively with the rising number of elderly people.

People age differently, as there are enormous differences among individuals. Bortz (1998) classified those between 65 and 75 years as young old; the old old as between 75 and 85 years, and the oldest old as 85 years and above. According to the US Bureau of the Census (2002), the number of people 75 years of age or older in 2005 was expected to be 17.7 million and, by 2020 , the number was expected to reach 21.8 million. As confirmed by WHO (1999), by 2050, there will be two billion people over the age of 60 years, with $80 \%$ of them living in developing countries.

A UN (2001) report indicated that by 2025, people aged 60 years and above in the developing world will have increased from 400 million to approximately 849 million, representing $70 \%$ of all older people worldwide. The report of a study by Help Age International (2002), among the aged in Ghana, revealed that those 80 years and above constituted the largest group (23.9\%), followed by $65-69$ years $(21.6 \%), 60-64$ years $(21.3 \%)$ and $70-74$ years (20.8\%).

In terms of gender difference, women live longer than men almost everywhere (WHO 2002). In 2002, there were 678 men for every 1,000 women aged 60 plus in Europe. In less developed regions, there were 879 men per 1,000 women (WHO 2002). The report added that women make up approximately two-thirds of the population over 75 years in countries such as Brazil and South Africa. While women have a longer life span, they are more likely than men to suffer disabilities in old age because of their second-class status, as the health of older women is neglected or ignored (UN 2001).

With ageing, a slight loss in overall stature occurs due to atrophy of the discs between the spinal vertebrae. Ligaments, tendons and joints are also affected by age. They become hardened, more rigid, less flexible and predisposed to tears. Cartilage wears down around the joints, making flexion painful. Rheumatoid arthritis also increases with age. As reported by Madden (2008), it affects approximately 387,000 adults in the UK. Rheumatoid arthritis is usually a progressive disease, although the degree of disease activity varies with each individual. As pointed out by Madden (2008), it can cause damage to the joints, resulting in stiffness, pain and reduced function.

Osteoarthritis is a degenerative condition of individual joints, and the parts of the body mostly affected are the weight-bearing joints, such as the feet, ankles, knees, wrists, elbows and shoulders. It is said to be two or three times as common in women as in men, with the average age of onset being 40 years and above, though it can occur in children, as stated by Meyer (2001), Oluruntoba (2009) and Murphree and Neighbors (2007).

Frequent and early occurrence of these age-related degenerative conditions create psychological and socioeconomic concern. People tend to spend more time in search of health services in order to cope with their jobs when they are expected to be active and economically productive in their workplaces. The literature reveals that aged people, especially women, are more likely to suffer chronic degenerative conditions and are most likely to use health serves more often (UN, 2001).

The aim of this retrospective study is to examine the incidence, age and gender distribution of osteoarthritis of the knee joints, and the joints of the lumbar and cervical spine among elderly people who used nursing and physiotherapy health services between July 2007 and June 2008 at the University of Ibadan Health Services Centre, Oyo State, Nigeria. It is hoped that the outcome of this study will encourage nurses and other stakeholders in the care of elderly people to be prepared to care and work more effectively with the rising number of the elderly.

\section{METHODOLOGY}

The study adopted a non-experimental descriptive design.

\section{Setting}

The study was done at the University Health Service Centre, University of Ibadan. The centre offers primary and secondary health services, and makes referral to the University College Hospital (UCH), Ibadan. The centre provides various health services to the entire staff of the university. It has various units: out patient unit, medical, nursing, physiotherapy, ophthalmic, immunization unit for children, antenatal, pharmacy and laboratory units. It also serves as a research centre.

\section{Sample and Sampling Method}

The study population consists of adult subjects who utilized nursing and physiotherapy health services between July 2007 and June 2008. 


\section{Sample Size}

Retrospective records of osteoarthritis patients between July 2007 and June 2008 were retrieved with the consent of the authority concerned. The record showed a total of 486 elderly patients diagnosed with osteoarthritis, comprised of 209 males and 277 females.

\section{Inclusion criteria}

All adults whose ages ranged between 45 and 85 years, and who had been diagnosed with osteoarthritis of either the knee joint, the lumbar or cervical spine were included in the study.

\section{Data collection}

Consent was obtained from the head of the health centre. Thereafter, records of old and new cases of osteoarthritis of either the knee joint, the lumbar or cervical spine among adults aged 45-85 years, who utilized nursing and health services in the study setting between July 2007 and June 2008, were retrieved retrospectively. The names and file numbers of the clients were not reflected in the study to ensure confidentiality.

\section{Data analysis}

Data was collated, edited manually and presented in a descriptive format using frequency counts and simple percentages. The chi-square test was used to determine the relationship between gender, age and occurrence of osteoarthritis

\section{RESULTS}

Out of the 486 cases of osteoarthritis seen between July, 2007 and June 2008, the incidence of osteoarthritis of the lumbar spine was the highest - 175 (36\%). Table 1 shows the gender distribution of the cases. Among the males, the incidence of osteoarthritis of the lumbar spine was the highest, followed by the cervical spine and the knee joint. Among the females, the incidence of osteoarthritis of the knee joint was the highest, followed by the cervical spine and the lumbar spine. There was a significant difference in the distribution of osteoarthritis between the males and females.

Tables 2 and 3 show the age distribution for osteoarthritis of the knee joint, lumbar and cervical spine. The chi-square test indicated that there was a significant difference in the distribution of osteoarthritis among the age groups. In the males, the incidence of osteoarthritis of the lumbar spine was the highest, and was found to be more common within the age groups of $61-65$, followed by 45 $50,56-60$ and 51-55. In the females, the incidence of osteoarthritis of the knee joint was the highest, and found to be more common within the age groups of 56-60, followed by $45-50,61-65,81-85$ and 71-75. Osteoarthritis of the cervical spine was the second most common in both males and females. It was found to be high within the age groups of 51-55, 71-75 and 45-50 among the males, while among the females, it was found to be high within the age groups of 51-55, 45-50, 56-60 and 66-70.

Table 1. Gender distribution of osteoarthritis of the knee joint, lumbar and cervical spine

\begin{tabular}{lcccccc}
\hline & $\begin{array}{c}\text { Male } \\
\mathrm{n}(\%)\end{array}$ & $\begin{array}{c}\text { Female } \\
\mathrm{n}(\%)\end{array}$ & $\begin{array}{c}\text { Total } \\
\mathrm{n}(\%)\end{array}$ & $\mathrm{X}^{2}$ & df & $\begin{array}{l}\mathrm{P} \\
\text { value }\end{array}$ \\
\hline Knee joint & $42(20.1)$ & $110(39.7)$ & $152(31.3)$ & & & \\
Lumbar spine & $103(49.3)$ & $72(26.0)$ & $175(36.0)$ & & & \\
Cervical spine & $64(30.6)$ & $95(34.3)$ & $159(32.7)$ & 27.397 & 2 & 0.000 \\
Total & $209(100)$ & $277(100)$ & $486(100)$ & & & \\
\hline
\end{tabular}

Table 2. Age distribution of osteoarthritis of the knee joint, lumbar and cervical spine among elderly male subjects

\begin{tabular}{|c|c|c|c|c|c|c|c|}
\hline $\begin{array}{l}\text { Age } \\
\text { (yrs) }\end{array}$ & $\begin{array}{c}\text { Osteoarthri- } \\
\text { tis of the } \\
\text { knee joint } \\
\text { n }(\%)\end{array}$ & $\begin{array}{c}\text { Lumbar } \\
\text { Spine } \\
\text { n }(\%)\end{array}$ & $\begin{array}{c}\text { Cervical } \\
\text { Spine } \\
\mathrm{n}(\%)\end{array}$ & Total & $X^{2}$ & $\mathrm{df}$ & $\begin{array}{l}P \\
\text { value }\end{array}$ \\
\hline $45-50$ & $13(31.0)$ & $20(19.4)$ & $9(14.1)$ & 42 & \multirow{8}{*}{66.867} & \multirow{8}{*}{12} & \multirow{8}{*}{0.000} \\
\hline $51-55$ & $15(35.7)$ & $13(12.6)$ & $21(32.8)$ & 49 & & & \\
\hline $56-60$ & $8(19)$ & $18(17.5)$ & 7 (10.9) & 33 & & & \\
\hline $61-65$ & $4(9.5)$ & $36(35.0)$ & $6(9.4)$ & 46 & & & \\
\hline $66-70$ & $2(4.8)$ & $10(9.7)$ & $6(9.4)$ & 18 & & & \\
\hline $71-75$ & - & $1(1.0)$ & $15(23.4)$ & 16 & & & \\
\hline $76-80$ & - & $5(4.8)$ & - & 5 & & & \\
\hline Total & $42(100)$ & $103(100)$ & $64(100)$ & 209 & & & \\
\hline
\end{tabular}

Table 3. Age distribution of osteoarthritis of the knee joint, lumbar and cervical spine among elderly female subjects

\begin{tabular}{|c|c|c|c|c|c|c|c|}
\hline $\begin{array}{l}\text { Age } \\
\text { (yrs) }\end{array}$ & $\begin{array}{l}\text { Osteoarthri- } \\
\text { tis of the } \\
\text { knee joint } \\
\text { n }(\%)\end{array}$ & $\begin{array}{c}\text { Lumbar } \\
\text { Spine } \\
\text { n }(\%)\end{array}$ & $\begin{array}{c}\text { Cervical } \\
\text { Spine } \\
\mathrm{n}(\%)\end{array}$ & Total & $\mathrm{X}^{2}$ & $\mathrm{df}$ & $\begin{array}{l}P \\
\text { value }\end{array}$ \\
\hline $45-50$ & $21(19.1)$ & $6(8.3)$ & $22(23.1)$ & 49 & \multirow{9}{*}{78.273} & \multirow{9}{*}{14} & \multirow{9}{*}{0.00} \\
\hline $51-55$ & $6(5.5)$ & $14(19.4)$ & $32(33.6)$ & 52 & & & \\
\hline $56-60$ & $36(32.7)$ & $18(25.0)$ & $18(19.0)$ & 72 & & & \\
\hline $61-65$ & $15(13.7)$ & $15(20.8)$ & $7(7.4)$ & 37 & & & \\
\hline $66-70$ & $4(3.6)$ & $139(18.1)$ & $13(13.7)$ & 30 & & & \\
\hline $71-75$ & $11(10.0)$ & $1(1.4)$ & $2(2.1)$ & 14 & & & \\
\hline $76-80$ & $3(3.6)$ & $5(7)$ & $1(1.1)$ & 10 & & & \\
\hline $81-85$ & $13(11.8)$ & - & - & 13 & & & \\
\hline Total & $110(100)$ & $72(100)$ & $95(100)$ & 277 & & & \\
\hline
\end{tabular}




\section{DISCUSSION}

The record of all the 486 subjects studied did not show any associated pathological condition. This suggests that the incidence of osteoarthritis in these clients could be linked to the ageing process, although other factors such as nature of their jobs, level of stress or genetic factor cannot be ruled out. These factors are also related to ageing in one way or the other (WHO, 2003).

The findings revealed that osteoarthritis occurred in different parts of the body of the subjects studied. While some had osteoarthritis of the knee joint, others had osteoarthritis of either the lumbar or cervical spine. This is attributed to the natural process of ageing. The result is consistent with Meyer's (2001) description of osteoarthritis as a degenerative condition affecting mostly the weightbearing joints, such as the knees, feet, ankles, elbows and shoulders, with average age of onset being 40 years and above. Different parts of the body begin to decline and deteriorate at different rates in individuals. This also accounts for the gender difference in the occurrence of osteoarthritis, although, the literature reveals that elderly women are more likely to suffer chronic degenerative conditions and are likely to use health services more often (UN, 2001).

In relation to age, the distribution of osteoarthritis cuts across ages, from $45-80$ years in males, and $45-85$ years in females, although at different rates. Among the males, 91 out of $209(43.5 \%)$ within the active age range of $45-55$ years presented with osteoarthritis of either the knee joint, the lumbar or the cervical spine, and started to use physiotherapy health services. Others presented with osteoarthritis after the retirement age of 65 years. About $10 \%$ presented within the age bracket of 71-80 years. A similar result was obtained among the females, but the results indicated that more females, $67(24.1 \%)$, presented at the age of 71-85 years, compared to 39 (18.7\%) males.

This study also revealed that many of the subjects were either close to or within the retirement age that is, $60-85$ years, which is considered old age, as reported by Bortz (1998). Those in this category constituted $60.5 \%$ of the study population. This suggests that the rate of elderly people utilizing nursing and physiotherapy health services is on the increase. This result is consistent with WHO's (1999) report that the proportion of poeple aged 60 years and above is growing faster than any other age group. As stated by WHO, by 2025 , there will be a total of about 1.2 billion people over the age of 60 years. A $2001 \mathrm{UN}$ report indicated that by 2025 , people aged 60 years and above in the developing countries, especially in Africa, will have increased from 400 million to approximately 849 million, representing $70 \%$ of all elderly people worldwide.

As noted by Chitty (2005), this category of old people are more likely than yonger people to suffer from chronic conditions such as arthritis. Huang (1999) also reported that the most frequently reported diagnosis of elderly people was arthritis, followed by osteoporosis. As a consequence, elderly people may continue to use a higher share of health services than other age groups, with people over 65 years having twice as many contacts with the health care system than those under 65 years (USAHHS, 1991 and USAHHS, 2002). As noted by Valentino (2002), the implication is that nurses of the future should be prepared to work efficiently with the rising number of elderly people.

\section{Implication for nursing}

An inference can be drawn from this study that cases of osteoarthritis can be found in general and teaching hospitals, either in relation to the ageing process or due to pathological conditions. Nurses working in these settings and those involved in family or home care should be aware of conditions prevalent at each stage of adulthood and the associated risk factors so as to assist people to age successfully and cope effectively with their conditions.

Nurses have been challenged by Valentino (2002) to be prepared to work effectively with the rising number of elderly people. As reported by Fajemilehin (2009), in most parts of the world today, elderly persons are a rapidly growing segment of the population. They are significant consumers of health care resources and, in the future, will continue to make heavy demands on the health and social coupled services. There may be need for the nursing profession to respond to the ageing population by increasing the number of courses offered in gerontological nursing to prepare nurses to care for elders more effectively, as suggested by Chitty (2005).

Nurses should be able to counsel adults of all ages, especially women, on the importance of calcium consumption. Elderly people need to be encouraged to exercise, especially walking, to promote flexibility (Amusat, 2009). Nurses need to perform passive range of motion exercises for those who need it. It is essential that nurses teach safety measures, including fall prevention. 


\section{CONCLUSION AND RECOMMENDATIONS}

The findings of this study suggest that the incidence of osteoarthritis seemed the same in males and females, but the distribution varied with the ages of the subjects. More than $60 \%$ of the study population with osteoarthritis of one part or the other were over 60 years, which corroborates the literature from other empirical studies. One of the limitations of this study was that the incidence of osteoarthritis in the study population could not be linked to their occupation.

Based on the findings and the limitations of the study, it is recommended that further studies be considered in the area of the relationship between the nature of a person's job and incidence of osteoarthritis. This could probably explain why osteoarthritis of the knee joint, the lumbar or cervical spine is peculiar to some individuals.

\section{References}

Amusat, N. 2009. Disability care in Nigeria: Tthe need for professional advocacy. African journal of physiotherapy and Rehabilitation Services 1(1): 30 - 36.

Bortz, W. 1998. Responding to the special needs of the elderly. In. DeLaune, S.C. and P.K. Ladner (eds.) Fundamentals of Nursing. Delmar Publishers, Albany. pp. 575-590.

Chitty, K.K. 2005. Professional Nursing: Concepts and Challenges. Elsevier Saunders. $4^{\text {th }}$ ed. St. Lois, Missouri. pp. 85-86, 333334.

Fajemilehin, B.R. 2009. Caring, health and longevity: Inaugural lecture delivered at Obafemi Awolowo University, Ile - Ife, Nigeria on May $12^{\text {th }}$. Obafemi Awolowo University Press Limited, Ile-Ife, Nigeria. pp. 47-99.

Help Age International 2002. Survey of Attitudes Towards Older People and Aging in Ghana. Retrieved from www.helpage.org 24/02/06.

Huang, L.H. 1999. The health status and needs of community elderly living alone. Curations 22(3): 100-105.
Madden, J. 2008. Managing patients with resistant rheumatoid arthritis. Nursing Standard 22(43): 51-59.

Meyer, J.A. 2001. The Princeton Review: Cracking the NCLEX$R N$. Princeton Review Publishing L.L.C. New York; 167-177.

Murphree, J.L. and M. Neighbors 2007. The aging population. In. Morahan, F.D., J.K. Sands, M. Neighbors, J.F. Marck and C.J. Green (Eds.). PHIPP's Medical-Surgical Nursing: Health and Illness Perspective. $8^{\text {th }}$ ed. Mosby Elsevier, St. Louis Missouri, USA. pp .10-29.

Oloruntoba, D.O. 2009. Bone and joint injuries. In. Adeloye, A., O. O. Adekunle and O.A. Awojobi (eds). Davey's Companion to Surgery in Africa. Acecool Medical Publishers (3rd ed). Eruwa, Nigeria, 29-32.

Oloruntoba, D. O. and Adeloye, A. (2009). Tuberculosis of the spine. In: A. Adeloye, O. O. Adekunle and O. A. Awojobi (eds). Davey's Companion to Surgery in Africa. Acecool Medical Publishers, 3rd ed. Eruwa, Nigeria, 213-219.

United Nations 2001. World Population Prospects: The 2000 Revision. Population Division, Department of Economic and Social Affairs. New York: NY.

US Bureau of the Census 2002. Statistical Abstract of the United States: $122^{\text {nd }}$ ed. Government Printing Office, Washington, DC.

US Department of Health and Human Service, Health Resources and Services Administration (USAHHS) (2002). Projected supply, demand and shortages of registered nurses: 2000-2020. Washington, DC. Government Printing Office.

US Department of Health and Human Services (USAHHS). (1991). A profile of older Americans. Washington, DC. Author.

Valentino, L.M. 2002. Future employment trends in nursing. American Journal of Nursing, 2002 Career guide.

WHO 2003. Facts about aging. Retrieved from www.afrowho.int/aging and health 15/03/06.

WHO 2002. Developing and validating a methodology to examine the impact of HIV/AIDS on older caregivers. Zimbabwe case study. World Health Organization, Geneva (in press).

WHO 1999. World Health Report Database. World Health Organization, Geneva 